\title{
Ethnic and socioeconomic differences in SARS-CoV-2 infection: prospective cohort study using UK Biobank
}

\author{
Claire L. Niedzwiedz', Catherine A. O'Donnell ${ }^{2}$, Bhautesh Dinesh Jani ${ }^{2}$, Evangelia Demou ${ }^{3}$, Frederick K. Ho ${ }^{1}$, \\ Carlos Celis-Morales ${ }^{1,4}$, Barbara I. Nicholl2 ${ }^{2}$ Frances S. Mair ${ }^{2}$, Paul Welsh ${ }^{4}$, Naveed Sattar ${ }^{4}$, Jill P. Pell ${ }^{1}$ and \\ S. Vittal Katikireddi ${ }^{3,5^{*}}$ (D)
}

\begin{abstract}
Background: Understanding of the role of ethnicity and socioeconomic position in the risk of developing SARSCoV-2 infection is limited. We investigated this in the UK Biobank study.

Methods: The UK Biobank study recruited 40-70-year-olds in 2006-2010 from the general population, collecting information about self-defined ethnicity and socioeconomic variables (including area-level socioeconomic deprivation and educational attainment). SARS-CoV-2 test results from Public Health England were linked to baseline UK Biobank data. Poisson regression with robust standard errors was used to assess risk ratios (RRs) between the exposures and dichotomous variables for being tested, having a positive test and testing positive in hospital. We also investigated whether ethnicity and socioeconomic position were associated with having a positive test amongst those tested. We adjusted for covariates including age, sex, social variables (including healthcare work and household size), behavioural risk factors and baseline health.

Results: Amongst 392,116 participants in England, 2658 had been tested for SARS-CoV-2 and 948 tested positive (726 in hospital) between 16 March and 3 May 2020. Black and south Asian groups were more likely to test positive (RR 3.35 (95\% Cl 2.48-4.53) and RR 2.42 (95\% Cl 1.75-3.36) respectively), with Pakistani ethnicity at highest risk within the south Asian group (RR 3.24 (95\% Cl 1.73-6.07)). These ethnic groups were more likely to be hospital cases compared to the white British. Adjustment for baseline health and behavioural risk factors led to little change, with only modest attenuation when accounting for socioeconomic variables. Socioeconomic deprivation and having no qualifications were consistently associated with a higher risk of confirmed infection (RR 2.19 for most deprived quartile vs least ( $95 \% \mathrm{Cl} 1.80-2.66)$ and RR 2.00 for no qualifications vs degree ( $95 \% \mathrm{Cl} 1.66-2.42)$ ).

Conclusions: Some minority ethnic groups have a higher risk of confirmed SARS-CoV-2 infection in the UK Biobank study, which was not accounted for by differences in socioeconomic conditions, baseline self-reported health or behavioural risk factors. An urgent response to addressing these elevated risks is required.
\end{abstract}

Keywords: Ethnicity, Inequality, Coronavirus, COVID-19, SARS-CoV-2, Health inequality, Infectious disease, Social factors, Pandemic

\footnotetext{
* Correspondence: vittal.katikireddi@glasgow.ac.uk

${ }^{3} \mathrm{MRC/CSO}$ Social \& Public Health Sciences Unit, University of Glasgow, Top floor, 200 Renfield Street, Glasgow G2 3QB, UK

${ }^{5}$ Public Health Scotland, Meridian Court, 5 Cadogan Street, Glasgow G2 6QE, UK

Full list of author information is available at the end of the article
}

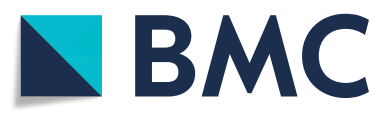

( The Author(s). 2020 Open Access This article is licensed under a Creative Commons Attribution 4.0 International License, which permits use, sharing, adaptation, distribution and reproduction in any medium or format, as long as you give appropriate credit to the original author(s) and the source, provide a link to the Creative Commons licence, and indicate if changes were made. The images or other third party material in this article are included in the article's Creative Commons licence, unless indicated otherwise in a credit line to the material. If material is not included in the article's Creative Commons licence and your intended use is not permitted by statutory regulation or exceeds the permitted use, you will need to obtain permission directly from the copyright holder. To view a copy of this licence, visit http://creativecommons.org/licenses/by/4.0/ The Creative Commons Public Domain Dedication waiver (http://creativecommons.org/publicdomain/zero/1.0/) applies to the data made available in this article, unless otherwise stated in a credit line to the data. 


\section{Background}

The severe acute respiratory syndrome coronavirus-2 (SARS-CoV-2) and its resulting disease (COVID-19) are spreading rapidly worldwide [1]. A better understanding of the predictors of developing infection is essential for health service planning (e.g. ensuring adequate facilities for those most at risk), targeting prevention efforts (e.g. targeted shielding or surveillance) and informing future modelling efforts. Age, male sex and pre-existing medical conditions are established predictors of adverse COVID-19 outcomes, as is excess adiposity [2], but the role of social determinants is poorly understood $[3,4]$.

Ethnicity and socioeconomic position strongly influence health outcomes for both infectious and noncommunicable diseases. Previous pandemics have often disproportionately impacted ethnic minorities and socioeconomically disadvantaged populations $[5,6]$. Early evidence suggests that the same may be occurring in the current SARS-CoV-2 pandemic but empirical research remains highly limited [7]. It is highly plausible that infection risk will vary across these social groups. For example, socioeconomic disadvantage is linked to living in overcrowded housing. Similarly, Bangladeshi, Indian and Chinese households are more likely to live in intergenerational households (e.g. with children, parents and grandparents) [8], which has been hypothesised to increase transmission [9].

Establishing the risk of developing infection across different social groups is challenging. A major issue is that information about ethnicity and socioeconomic position are often not well collected within routine health data. Furthermore, the size of the different social groups in the general population is also often not accurately known [10]. The ideal approach to estimating infection risk across different social groups is to analyse data from a cohort study, but most existing cohort studies which include detailed information about ethnicity and socioeconomic position are subject to long delays in data being available for analysis and are too small to provide useful estimates of infection risk.

The UK Biobank study has carried out data linkage between its study participants and SARS-CoV-2 test results held by Public Health England. We therefore aimed to investigate the relationship between ethnicity, socioeconomic position and the risk of having confirmed SARSCoV-2 infection in the population-based UK Biobank study.

\section{Methods}

\section{Study design and participants}

Data were obtained from UK Biobank (https://www. ukbiobank.ac.uk/), with the methods described in detail previously [11]. In brief, over 502,000 communitydwelling individuals largely aged 40 to 70 years were recruited to the study during 2006 to 2010. Participants attended one of 22 assessment centres across England, Scotland and Wales. Data were collected on a range of topics including social and demographic factors, health and behavioural risk factors, using standardised questionnaires administered by trained interviewers and selfcompletion by computer.

Results of SARS-CoV-2 tests for UK Biobank participants, including confirmed cases, were provided by the Public Health England (PHE) microbiology database Second Generation Surveillance System and linked to UK Biobank baseline data [12]. Data provided by PHE included the specimen date, specimen type (e.g. upper respiratory tract), laboratory, origin (whether there was evidence from microbiological record that the participant was an inpatient or not) and result (positive or negative). Data were available for the period 16 March 2020 to 3 May 2020.

Since data on test results were only available for England, we restricted the study population to people who attended UK Biobank baseline assessment centres in England. Participants who were identified as having died prior to 31 January 2018 from the linked mortality records provided by the NHS Information Centre $(N=17$, 632) and those who requested to withdraw from the study prior to February $2020(N=30)$ were also excluded from the analysis. In addition to the analyses of the overall population, we also investigated positive test results amongst those who had been tested only. This allowed us to investigate the potential for bias due to differential testing between ethnic and socioeconomic groups. UK Biobank received ethical approval from the NHS National Research Ethics Service North West (11/NW/0382; 16/NW/0274).

\section{Assessment of ethnicity and socioeconomic position}

All exposures were derived from the baseline assessment centre data collection. Ethnicity was self-reported and categorised into white British, white Irish, other white background, south Asian, black (Caribbean or African), Chinese, mixed or others. As more data became available, we also used more refined groupings, separating south Asian into Indian, Pakistani or other south Asians (including Bangladeshi) and black into Carribean, African or other black. Due to small numbers, analyses of the Chinese, mixed and other black groups were limited. In line with previous research, we also do not report results for the other group due to problems with interpretation of this highly heterogenous group [13].

Socioeconomic position was assessed using two different measures recorded at the baseline visit. Area-level socioeconomic deprivation was assessed by the Townsend index (including measures of unemployment, noncar ownership, non-home ownership and household 
overcrowding), corresponding to the output area in which the respondent's home postcode was recorded [14]. Quartiles were derived from the index, where the lowest quartile represents the most advantaged and the highest the least advantaged. Highest education level is a proxy measure for socioeconomic position and usually remains stable throughout the adult life course. It was assessed as (1) university or college degree; (2) A levels or equivalent; (3) O levels, General Certificate of Secondary Education (GCSE), vocational Certificate of Secondary Education (CSE) or equivalent; (4) others (e.g. National Vocational Qualifications or other professional qualifications); or (5) none of the above [15].

\section{Ascertainment of SARS-CoV-2 outcomes}

We defined our primary outcome as having a positive test within the Public Health England database available through linkage [12]. This reflects confirmed infection but does not include symptomatic individuals who have not presented to the health service or not been tested, or asymptomatic cases. Some systemic differences exist in testing threshold. For example, healthcare workers may be more likely to be tested and therefore observed differences may reflect differences in testing practices. To investigate whether differential ascertainment was biasing our results, we studied three further outcomes. We identified positive cases that had their test taken while attending hospital (i.e. either emergency departments or as inpatients-hereafter referred to as hospital cases). This group is likely to reflect more severe illness and therefore is less likely to be subject to ascertainment bias. In addition, we investigated outcomes related to testing practice by assessing the risk of being tested in the overall population and testing positive amongst only those who had been tested. Higher levels of confirmed SARSCoV-2 infection could arise from higher rates of testing amongst some population subgroups [12]. However, if this were to occur, the likelihood of having a positive test would be lower amongst groups experiencing high rates of testing.

\section{Potential confounders and mediators}

Age group (5-year age bands), sex and assessment centre were included as potential confounding variables in all statistical models. Country of birth (UK and Ireland) versus elsewhere was also included, given its influence on cultural practices [16]. We also included several variables which could reflect potential confounding or mediation.

Baseline health status was assessed using self-reported longstanding illness, disability or infirmity (yes or no), self-reported health status (excellent, good, fair, poor) and the number of chronic health conditions selfreported from a pre-defined list of 43 conditions and top-coded at 4 or more, based on a previously published approach [17]. Behavioural factors included smoking (never, previous, current), body mass index (BMI) (weight/height ${ }^{2}$ derived from physical measurements and classified into underweight, normal weight, overweight, obese) and alcohol consumption (categorised into daily or almost daily, 3-4 times a week, once or twice a week, 1-3 times per month, special occasions, former drinker or never).

Other social variables were also considered. Employment status distinguished those in paid employment or self-employment, retired, looking after home and/or family, unable to work because of sickness or disability, unemployment or others. For those in work, manual versus non-manual occupation was assessed by asking participants to report whether their job involved heavy manual or physical work (never/rarely/sometimes versus usually/always). Participants were asked about the title of their current or most recent job at baseline and these were converted to the Standard Occupational Classification (SOC 2000 [18]) by UK Biobank. Healthcare (and related) workers were identified from the SOC 2000 codes 22 (Health Professionals), 32 (Health and Social Welfare Associate Professionals), 118 (Health and Social Services Managers), 611 (Healthcare and Related Personal Services), 9221 (Hospital porters) and 4211 (Medical Secretaries). Housing tenure was categorised into owner-occupier or renter/other (including those who lived in accommodation rent free, in a care home or sheltered accommodation). Urban/rural status was derived from data on the home area population density; UK Biobank combined each participant's home postcode with data generated from the 2001 census from the Office of National Statistics. The number of people within a household was categorised into four groups: single person, two people, three people or four or more people (which included those living in institutions, such as care homes).

\section{Statistical analyses}

The association between the exposures (ethnicity and socioeconomic position) and the outcomes of interest (confirmed infection, hospital case, being tested and having a positive test amongst those tested) was explored using Poisson regression. Poisson regression was preferred over logistic regression to allow relative risks to be presented, rather than odds ratios which are often misinterpreted [19]. Robust standard errors were used to ensure accurate estimation of 95\% confidence intervals and $p$ values. Missing data were excluded from the analysis via listwise deletion. Statistical analysis was conducted using Stata/MP 15.1.

To investigate ethnic differences, we initially adjusted for age, sex and assessment centre (model 1) and then 
Table 1 Description of the study population

\begin{tabular}{|c|c|c|}
\hline & Number & Percentage \\
\hline \multicolumn{3}{|l|}{ Tested for SARS-CoV-2 } \\
\hline No & 389,458 & 99.3 \\
\hline Yes & 2658 & 0.7 \\
\hline \multicolumn{3}{|l|}{ Tested positive for SARS-CoV-2 } \\
\hline No & 391,168 & 99.8 \\
\hline Yes & 948 & 0.2 \\
\hline \multicolumn{3}{|c|}{ Tested positive for SARS-CoV-2 in hospital } \\
\hline No & 391,390 & 99.8 \\
\hline Yes & 726 & 0.2 \\
\hline \multicolumn{3}{|l|}{ Age group at baseline } \\
\hline $40-44$ & 40,995 & 10.5 \\
\hline $45-49$ & 52,116 & 13.3 \\
\hline $50-54$ & 60,291 & 15.4 \\
\hline $55-59$ & 71,160 & 18.1 \\
\hline $60-64$ & 95,604 & 24.4 \\
\hline $65-69$ & 70,110 & 17.9 \\
\hline $70+$ & 1840 & 0.5 \\
\hline \multicolumn{3}{|l|}{ Sex } \\
\hline Female & 215,351 & 54.9 \\
\hline Male & 176,765 & 45.1 \\
\hline \multicolumn{3}{|l|}{ Ethnicity } \\
\hline White British & 348,735 & 88.9 \\
\hline White Irish & 9800 & 2.5 \\
\hline White Other & 12,925 & 3.3 \\
\hline Mixed & 2356 & 0.6 \\
\hline Indian & 4571 & 1.2 \\
\hline Pakistani & 1259 & 0.3 \\
\hline Other South Asian & 1493 & 0.4 \\
\hline Black Caribbean & 3669 & 0.9 \\
\hline Black African & 2623 & 0.7 \\
\hline Black Other & 103 & 0.0 \\
\hline Chinese & 1153 & 0.3 \\
\hline Others & 3429 & 0.9 \\
\hline \multicolumn{3}{|l|}{ Country of birth } \\
\hline UK and Ireland & 361,025 & 92.1 \\
\hline Elsewhere & 31,091 & 7.9 \\
\hline \multicolumn{3}{|l|}{ Number in household } \\
\hline 1 & 69,862 & 17.8 \\
\hline 2 & 183,777 & 46.9 \\
\hline 3 & 62,934 & 16.0 \\
\hline $4+$ & 75,543 & 19.3 \\
\hline \multicolumn{3}{|l|}{ Education level } \\
\hline College or university degree & 128,890 & 32.9 \\
\hline A levels/AS levels & 44,650 & 11.4 \\
\hline
\end{tabular}


Table 1 Description of the study population (Continued)

\begin{tabular}{|c|c|c|}
\hline & Number & Percentage \\
\hline O levels/GCSEs/CSEs & 108,648 & 27.7 \\
\hline Others & 46,393 & 11.8 \\
\hline None of the above & 63,535 & 16.2 \\
\hline \multicolumn{3}{|l|}{ Deprivation quartile } \\
\hline Quartile 1 (most advantaged) & 100,701 & 25.7 \\
\hline Quartile 2 & 99,838 & 25.5 \\
\hline Quartile 3 & 98,380 & 25.1 \\
\hline Quartile 4 (least advantaged) & 93,197 & 23.8 \\
\hline \multicolumn{3}{|l|}{ Housing tenure } \\
\hline Own & 352,079 & 89.8 \\
\hline Rent/others & 40,037 & 10.2 \\
\hline \multicolumn{3}{|l|}{ Urban/rural } \\
\hline Urban & 334,570 & 85.3 \\
\hline Rural & 57,546 & 14.7 \\
\hline \multicolumn{3}{|l|}{ Employment status } \\
\hline In paid employment or self-employed & 230,190 & 58.7 \\
\hline Retired & 128,613 & 32.8 \\
\hline Looking after home and/or family & 10,956 & 2.8 \\
\hline Unable to work because of sickness or disability & 11,111 & 2.8 \\
\hline Unemployed & 6386 & 1.6 \\
\hline Others & 4860 & 1.2 \\
\hline \multicolumn{3}{|l|}{ Manual occupation } \\
\hline Non-manual & 199,564 & 50.9 \\
\hline Manual & 30,626 & 7.8 \\
\hline Not in employment & 161,926 & 41.3 \\
\hline \multicolumn{3}{|l|}{ Healthcare worker } \\
\hline No & 204,254 & 52.1 \\
\hline Yes & 25,936 & 6.6 \\
\hline Not in employment & 161,926 & 41.3 \\
\hline \multicolumn{3}{|l|}{ Long-standing illness, disability or infirmity } \\
\hline No & 268,919 & 68.6 \\
\hline Yes & 123,197 & 31.4 \\
\hline \multicolumn{3}{|l|}{ Number of chronic conditions } \\
\hline 0 & 147,943 & 37.7 \\
\hline 1 & 130,034 & 33.2 \\
\hline 2 & 69,222 & 17.7 \\
\hline 3 & 28,957 & 7.4 \\
\hline $4+$ & 15,960 & 4.1 \\
\hline \multicolumn{3}{|l|}{ Overall health rating } \\
\hline Excellent & 65,560 & 16.7 \\
\hline Good & 231,672 & 59.1 \\
\hline Fair & 79,347 & 20.2 \\
\hline Poor & 15,537 & 4.0 \\
\hline
\end{tabular}

BMI category 
Table 1 Description of the study population (Continued)

\begin{tabular}{lll}
\hline & Number & Percentage \\
\hline Underweight (<18.5) & 1928 & 0.5 \\
Normal weight (18.5-24.9) & 129,755 & 33.1 \\
Overweight (25.0-29.9) & 166,979 & 42.6 \\
Obese ( $\geq$ 30.0) & 93,454 & 23.8 \\
Smoking status & & 55.4 \\
Never & 217,297 & 34.8 \\
Previous & 136,482 & 9.8 \\
Current & 38,337 & \\
Alcohol consumption & & 20.8 \\
Daily or almost daily & 81,567 & 23.5 \\
Three or four times a week & 92,308 & 25.7 \\
Once or twice a week & 100,956 & 11.2 \\
One to three times a month & 43,743 & 11.2 \\
Special occasions only & 43,916 & 3.4 \\
Never (former drinker) & 13,315 & 4.2 \\
Never & 16,311 & 100.0 \\
Total & 392,116 & \\
\hline
\end{tabular}

added country of birth (model 2). Subsequent models additionally adjusted for variables which we hypothesised were likely to be at least partially mediating rather than confounding variables. Model 3 adjusted for model 2 variables and for being a healthcare worker. Model 4 additionally adjusted for social variables (namely urbanicity, number of people per household, highest education level, socioeconomic deprivation, tenure status, employment status, manual work); model 5 was adjusted for model 2 plus health status variables (self-rated health, number of chronic conditions and longstanding illness or disability); model 6 was adjusted for model 2 plus behavioural risk factors (smoking, alcohol consumption and BMI); and model 7 was adjusted for all aforementioned covariates. In post hoc analyses, we also repeated the above with the more defined ethnic groups.

We followed a similar approach to explore the role of socioeconomic deprivation and education level. Model 1 was adjusted for age, sex and assessment centre; model 2 added ethnicity and country of birth; model 3 also adjusted for the social variables (as above); model 4 adjusted for model 2 plus health status variables; model 5 was adjusted for model 2 plus behavioural risk factors; and model 6 was adjusted for all previous covariates.

\section{Results}

A total of 392,116 participants were included in the study (after excluding 36,109 (8.4\%) people with missing data, Additional file Figure S1 for flowchart and Table S1 for patterns of missing data by ethnicity and socioeconomic position). Most of the baseline UK Biobank sample in England was white British, with the next largest groups being other white, white Irish and then south Asian and black (Table 1 and Additional file Table S2). Approximately one-third (32.9\%) of the sample had a degree and $16.2 \%$ had no formal qualifications. In our sample, 2658 people had been tested for SARS-CoV-2 and 948 had at least one positive test $(726$ received a positive test in a hospital setting suggesting more severe illness) (see Additional file Table S3 for outcomes by ethnicity, socioeconomic deprivation and education level). The geometric mean number of tests performed per participant tested was 1.53 (95\% CI 1.50-1.56).

In comparison to the white British majority ethnic group, several ethnic minority groups had a higher risk of testing positive for SARS-CoV-2 infection and also testing positive while attending hospital (Fig. 1 and Additional file: Tables S4 and S5). Black participants had the highest risk (RR 3.35 (95\% CI 2.48-4.53)), with adjustment for the country of birth resulting in little attenuation (RR 3.13 (95\% CI 2.18-4.48)); adjustment for a history of being a healthcare worker (RR 2.66 (95\% CI 1.83-3.84)) and for social factors (including measures of socioeconomic position) did additionally attenuate the risk (RR 2.05 (95\% CI 1.39-3.03)). South Asians also had an elevated risk of testing positive (RR 2.42 (95\% CI 1.75-3.36) in model 1), with a broadly similar pattern of attenuation as for the black ethnic group. The white Irish group also had a marginally elevated risk of having a positive test (RR 1.42 (95\% CI 1.00-2.03)) which attenuated with adjustment for social variables (RR 1.23 (95\% CI 0.86-1.75). The Chinese group had imprecisely 


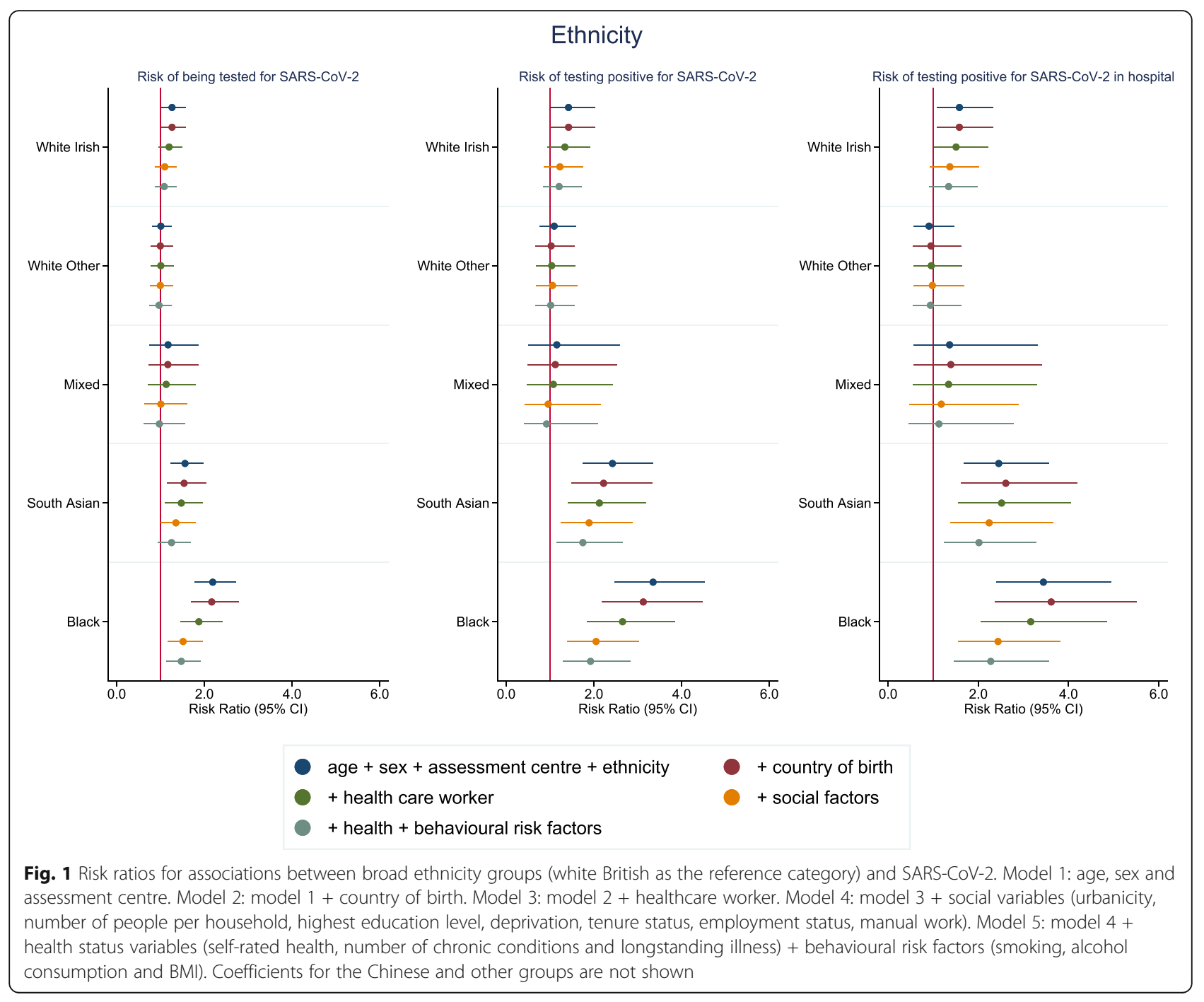

estimated risk ratios due to smaller numbers. The pattern of findings for hospital cases was similar (Additional file S5), suggesting that the higher testing rates amongst certain ethnic groups in the community were not skewing the results. Similarly, analyses of the likelihood of testing positive amongst those who had been tested were often higher or the same in these ethnic groups (Table 2 and Additional file S16), whereas a lower risk would have suggested differentially high testing.

When using a more detailed ethnicity classification within the south Asian and black groups, we observed important heterogeneity in the pattern of findings between the Indian group and other south Asian groups (Fig. 2 and Additional file Tables S7-S9). Compared to white British, risks were largest in the Pakistani group (RR 3.24 (95\% CI 1.73-6.07)), followed by other south Asians (RR 3.00 (95\% CI 1.64-5.49)) and were more modestly increased in the Indian group (RR 1.98 (95\% CI 1.26-3.09)). There were less clear differences in the estimates for black Caribbeans and black Africans: RR 3.51 (95\% CI 2.39-5.15) and RR 3.11 (95\% CI 1.97-4.91) in initial models and RR 2.18 (95\% CI 1.43-3.32) and RR 1.53 (95\% CI $0.87-2.69)$ in fully adjusted models respectively.

In comparison to the most socioeconomically advantaged quartile, living in a disadvantaged area (according to the Townsend deprivation score) was associated with a higher risk of confirmed infection, particularly for the most disadvantaged quartile (RR 2.19 (95\% CI 1.802.66)) (Fig. 3 and Additional file: Table S10). Differences in ethnicity and country of birth, social factors, baseline health and behavioural risk factors all moderately attenuated the association in the most disadvantaged quartile. Socioeconomic deprivation was also associated with hospital cases (Additonal file: Table S11). While testing was again more likely, the risk of being diagnosed positive amongst those tested also tended to be higher, rather than lower (Table 2 and Additional file: Table S17). 
Table 2 Risk ratios for testing positive for SARS-CoV-2 amongst those tested ( $N=2658)$ in UK Biobank

\begin{tabular}{|c|c|c|c|c|c|c|}
\hline & Model 1 & Model 2 & Model 3 & Model 4 & Model 5 & Model 6 \\
\hline & $\mathrm{RR}[95 \% \mathrm{Cl}]$ & $\operatorname{RR}[95 \% \mathrm{Cl}]$ & RR $[95 \% \mathrm{Cl}]$ & $\operatorname{RR}[95 \% \mathrm{Cl}]$ & $\mathrm{RR}[95 \% \mathrm{Cl}]$ & RR [95\% Cl] \\
\hline \multicolumn{7}{|l|}{ Ethnicity } \\
\hline White British (reference group) & 1.000 & 1.000 & 1.000 & 1.000 & 1.000 & 1.000 \\
\hline White Irish & $\begin{array}{l}1.166 \\
{[0.877,1.549]}\end{array}$ & $\begin{array}{l}1.165 \\
{[0.877,1.548]}\end{array}$ & $\begin{array}{l}1.133 \\
{[0.853,1.505]}\end{array}$ & $\begin{array}{l}1.169 \\
{[0.877,1.556]}\end{array}$ & $\begin{array}{l}1.150 \\
{[0.866,1.527]}\end{array}$ & $\begin{array}{l}1.132 \\
{[0.851,1.507]}\end{array}$ \\
\hline White Other & $\begin{array}{l}1.093 \\
{[0.814,1.467]}\end{array}$ & $\begin{array}{l}1.034 \\
{[0.737,1.452]}\end{array}$ & $\begin{array}{l}1.020 \\
{[0.718,1.448]}\end{array}$ & $\begin{array}{l}1.045 \\
{[0.743,1.470]}\end{array}$ & $\begin{array}{l}1.037 \\
{[0.739,1.454]}\end{array}$ & $\begin{array}{l}1.020 \\
{[0.718,1.449]}\end{array}$ \\
\hline South Asian & $\begin{array}{l}1.490^{* * *} \\
{[1.189,1.868]}\end{array}$ & $\begin{array}{l}1.384^{*} \\
{[1.011,1.894]}\end{array}$ & $\begin{array}{l}1.270 \\
{[0.917,1.759]}\end{array}$ & $\begin{array}{l}1.382^{*} \\
{[1.009,1.892]}\end{array}$ & $\begin{array}{l}1.355 \\
{[0.974,1.885]}\end{array}$ & $\begin{array}{l}1.279 \\
{[0.908,1.802]}\end{array}$ \\
\hline Black & $\begin{array}{l}1.489^{* * *} \\
{[1.215,1.825]}\end{array}$ & $\begin{array}{l}1.405^{*} \\
{[1.075,1.836]}\end{array}$ & $\begin{array}{l}1.324^{*} \\
{[1.011,1.734]}\end{array}$ & $\begin{array}{l}1.388^{*} \\
{[1.062,1.813]}\end{array}$ & $\begin{array}{l}1.355^{*} \\
{[1.031,1.781]}\end{array}$ & $\begin{array}{l}1.289 \\
{[0.978,1.699]}\end{array}$ \\
\hline \multicolumn{7}{|l|}{ Socioeconomic deprivation } \\
\hline Quartile 1 (most advantaged, reference group) & 1.000 & 1.000 & 1.000 & 1.000 & 1.000 & 1.000 \\
\hline Quartile 2 & $\begin{array}{l}1.035 \\
{[0.874,1.224]}\end{array}$ & $\begin{array}{l}1.039 \\
{[0.878,1.229]}\end{array}$ & $\begin{array}{l}1.023 \\
{[0.865,1.210]}\end{array}$ & $\begin{array}{l}1.039 \\
{[0.878,1.229]}\end{array}$ & $\begin{array}{l}1.035 \\
{[0.875,1.225]}\end{array}$ & $\begin{array}{l}1.020 \\
{[0.862,1.207]}\end{array}$ \\
\hline Quartile 3 & $\begin{array}{l}1.050 \\
{[0.894,1.233]}\end{array}$ & $\begin{array}{l}1.039 \\
{[0.884,1.220]}\end{array}$ & $\begin{array}{l}1.012 \\
{[0.861,1.191]}\end{array}$ & $\begin{array}{l}1.041 \\
{[0.885,1.223]}\end{array}$ & $\begin{array}{l}1.028 \\
{[0.875,1.207]}\end{array}$ & $\begin{array}{l}1.011 \\
{[0.860,1.190]}\end{array}$ \\
\hline Quartile 4 (least advantaged) & $\begin{array}{l}1.209^{*} \\
{[1.038,1.408]}\end{array}$ & $\begin{array}{l}1.164 \\
{[0.997,1.358]}\end{array}$ & $\begin{array}{l}1.135 \\
{[0.962,1.340]}\end{array}$ & $\begin{array}{l}1.158 \\
{[0.989,1.355]}\end{array}$ & $\begin{array}{l}1.133 \\
{[0.968,1.326]}\end{array}$ & $\begin{array}{l}1.114 \\
{[0.943,1.316]}\end{array}$ \\
\hline \multicolumn{7}{|l|}{ Education level } \\
\hline College or university degree (reference group) & 1.000 & 1.000 & 1.000 & 1.000 & 1.000 & 1.000 \\
\hline A levels/AS levels or equivalent & $\begin{array}{l}1.049 \\
{[0.867,1.270]}\end{array}$ & $\begin{array}{l}1.057 \\
{[0.873,1.279]}\end{array}$ & $\begin{array}{l}1.060 \\
{[0.877,1.282]}\end{array}$ & $\begin{array}{l}1.048 \\
{[0.866,1.269]}\end{array}$ & $\begin{array}{l}1.045 \\
{[0.862,1.265]}\end{array}$ & $\begin{array}{l}1.043 \\
{[0.862,1.262]}\end{array}$ \\
\hline O levels/GCSEs/CSEs or equivalent & $\begin{array}{l}1.121 \\
{[0.971,1.295]}\end{array}$ & $\begin{array}{l}1.135 \\
{[0.982,1.311]}\end{array}$ & $\begin{array}{l}1.131 \\
{[0.976,1.311]}\end{array}$ & $\begin{array}{l}1.132 \\
{[0.979,1.309]}\end{array}$ & $\begin{array}{l}1.093 \\
{[0.945,1.263]}\end{array}$ & $\begin{array}{l}1.092 \\
{[0.942,1.266]}\end{array}$ \\
\hline Others & $\begin{array}{l}1.310^{* *} \\
{[1.111,1.544]}\end{array}$ & $\begin{array}{l}1.301^{* *} \\
{[1.104,1.533]}\end{array}$ & $\begin{array}{l}1.236^{*} \\
{[1.045,1.461]}\end{array}$ & $\begin{array}{l}1.306^{* *} \\
{[1.107,1.541]}\end{array}$ & $\begin{array}{l}1.257^{* *} \\
{[1.066,1.482]}\end{array}$ & $\begin{array}{l}1.207^{*} \\
{[1.019,1.428]}\end{array}$ \\
\hline None of the above & $\begin{array}{l}1.227^{* *} \\
{[1.055,1.428]}\end{array}$ & $\begin{array}{l}1.230^{* *} \\
{[1.057,1.430]}\end{array}$ & $\begin{array}{l}1.210^{*} \\
{[1.032,1.419]}\end{array}$ & $\begin{array}{l}1.228^{* *} \\
{[1.053,1.432]}\end{array}$ & $\begin{array}{l}1.188^{*} \\
{[1.018,1.386]}\end{array}$ & $\begin{array}{l}1.180^{*} \\
{[1.005,1.385]}\end{array}$ \\
\hline
\end{tabular}

Note: RRs shown are for the relationship between each variable shown and the risk of testing positive amongst those who have had a test. Coefficients for the Chinese, mixed and other groups and for the covariates included are not shown. $R R$ risk ratio. $95 \%$ confidence intervals in brackets

Model 1: Adjusted for age, sex, assessment centre

Model 2: 1 + ethnicity, country of birth

Model 3: 2 + education level, household size, socioeconomic deprivation, housing tenure, urbanicity, employment status, manual occupation, healthcare worker Model 4: 2 + longstanding illness/disability, number of chronic conditions, self-rated health

Model 5: 2 + body mass index, smoking status, alcohol consumption

Model 6: All of the above covariates

${ }^{*} p<0.05,{ }^{* *} p<0.01,{ }^{* * *} p<0.001$

Analyses by education level also showed a higher risk of confirmed SARS-CoV-2 infection with the lowest level of education (RR 2.00 (95\% CI 1.66-2.42) for no qualifications compared to degree level educated) (Fig. 4 and Additional file: Table S13). While adjustment for ethnicity and country of birth made little difference to the association, adjustment for social factors, baseline health and behavioural risk factors all attenuated the association somewhat (RR 1.46 (95\% CI 1.19-1.79) in fully adjusted model). We again observed a similar pattern in hospital cases and found little evidence of increased testing amongst the less educated groups (Fig. 4 and Additional file Tables S14 and S18).

\section{Discussion}

Several ethnic minority groups had a higher risk of both being diagnosed and testing positive in a hospital setting with laboratory-confirmed SARS-CoV-2 infection in the UK Biobank study. The black and south Asian groups were found to be at greatest risk, with Pakistani ethnicity at greatest risk within the south Asian group. Similarly, measures of socioeconomic disadvantage (area-based deprivation and lower education) were also associated with an increased risk of having confirmed infection and being a hospital case. For both ethnicity and socioeconomic position, we did not find evidence that these patterns were likely to be due to differential ascertainment, 


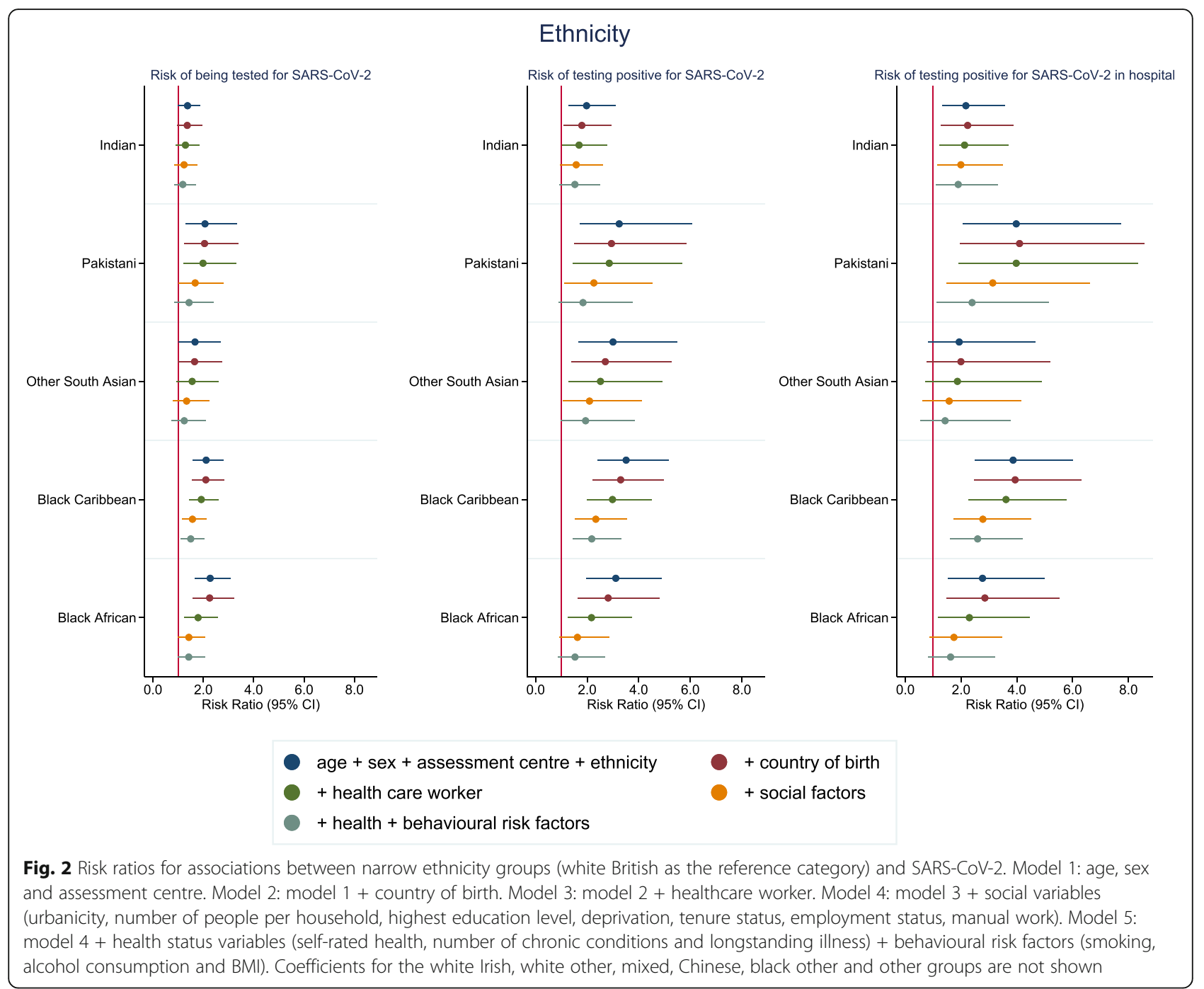

since although the likelihood of testing was increased, the likelihood of a positive test was, if anything, higher amongst ethnic minorities who had been tested. Ethnic differences in infection risk did not appear to be fully accounted for by differences in pre-existing health, behavioural risk factors or country of birth measured at baseline. Furthermore, socioeconomic differences appeared to make a moderate contribution to these ethnic differences.

Our study has several important strengths. First, by using a well-characterised cohort study, we can identify a clearly defined population at risk of experiencing SARS-CoV-2 infection. By combining data linkage with a large sample size, this has allowed us to provide empirical data from this pandemic in a timely fashion. Ethnicity was collected using self-report which is widely considered to be a gold standard approach [20], and the availability of a large dataset has allowed us to provide empirical data on this crucial policy priority in a timely fashion, including a more nuanced appreciation of the risks of infection within different members of the white majority population, as well as drilling down into more specific minority ethnic groups [21]. Our investigation of socioeconomic position has similarly benefited from being able to study different measures and assess the pattern of findings across these. The detailed data collected in this cohort has also allowed us to investigate the extent to which observed inequalities are potentially mediated by a wide range of factors, including behavioural risk factors, pre-existing health status and other social variables.

However, several potential limitations should be noted. Ascertainment bias is potentially problematic and could arise in several ways, including differential healthcare seeking, differential testing and differential prognosis. Even so, we have been unable to find any evidence to suggest that differential healthcare seeking or testing would explain the observed pattern of findings. 


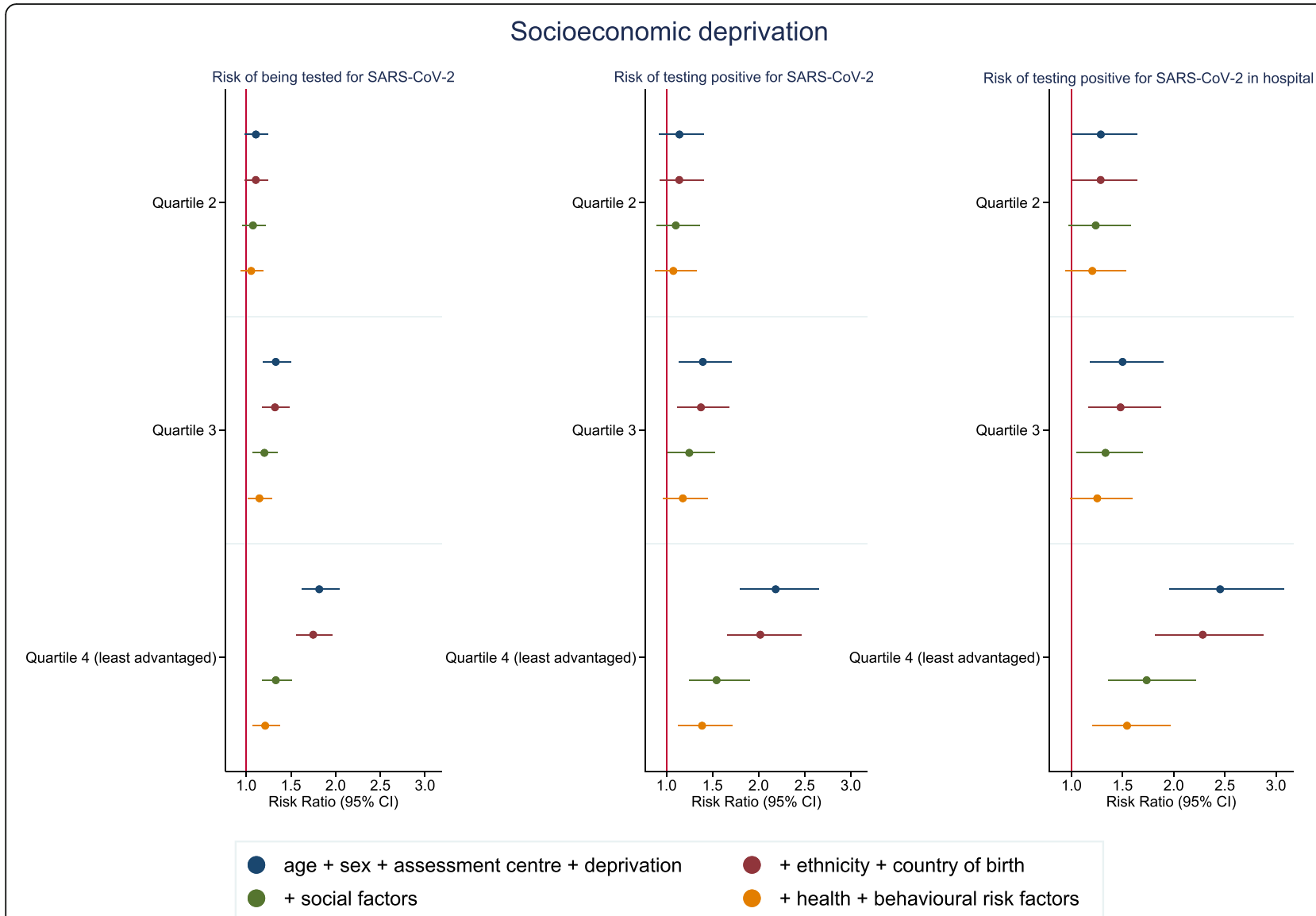

Fig. 3 Risk ratios for associations between Townsend deprivation score quartile (most advantaged as reference category) and SARS-CoV-2. Model 1: age, sex and assessment centre. Model 2: model $1+$ ethnicity + country of birth. Model 3: model $2+$ social variables (healthcare worker, urbanicity, number of people per household, highest education level, tenure status, employment status, manual work). Model 4: model $3+$ health status variables (self-rated health, number of chronic conditions and longstanding illness) + behavioural risk factors (smoking, alcohol consumption and BMI)

Increased ascertainment amongst ethnic minorities would be expected to result in a lower proportion of confirmed cases amongst those tested whereas we observed the opposite. One possibility that remains is that some ethnic and socioeconomic groups have a poorer prognosis and are therefore more likely to be admitted to hospital and therefore to be tested [7]. However, if this were the case, the issue of more adverse outcomes amongst these groups remains concerning. Other limitations include the non-representativeness of the UK Biobank study population, potentially exacerbated by missing data, with those who were more advantaged being more likely to participate and ethnic minorities less well represented. There is therefore the potential that the findings in our study may not reflect the broader UK population [22, 23]. However, empirical research has found that this may not result in substantial bias in measures of association in the UK Biobank study [24]. Furthermore, estimates from other sources of inequalities in COVID-19 mortality show similar patterns of associations to our results $[25,26]$. We have also been unable to fully exclude all deaths that occurred prior to the pandemic, due to lack of up-to-date linkage to mortality records at present. Our exposure data were collected some years ago, and it is therefore likely that pre-existing health, risk factors and some social variables have changed, although generally most risk factors track throughout life [27]. However, it is possible that management for chronic health conditions could have been differential across ethnic and socioeconomic groups [28] between baseline data collection and the pandemic period. Being a healthcare worker was also ascertained at baseline, although many who stopped employment in this area have now returned to work [29]. Lastly, due to sparse data, we have not explored the role of specific health conditions such as asthma, diabetes and high blood pressure, which have been shown to be associated with a higher risk of severe outcomes [3, 30] and are more prevalent amongst socioeconomically 


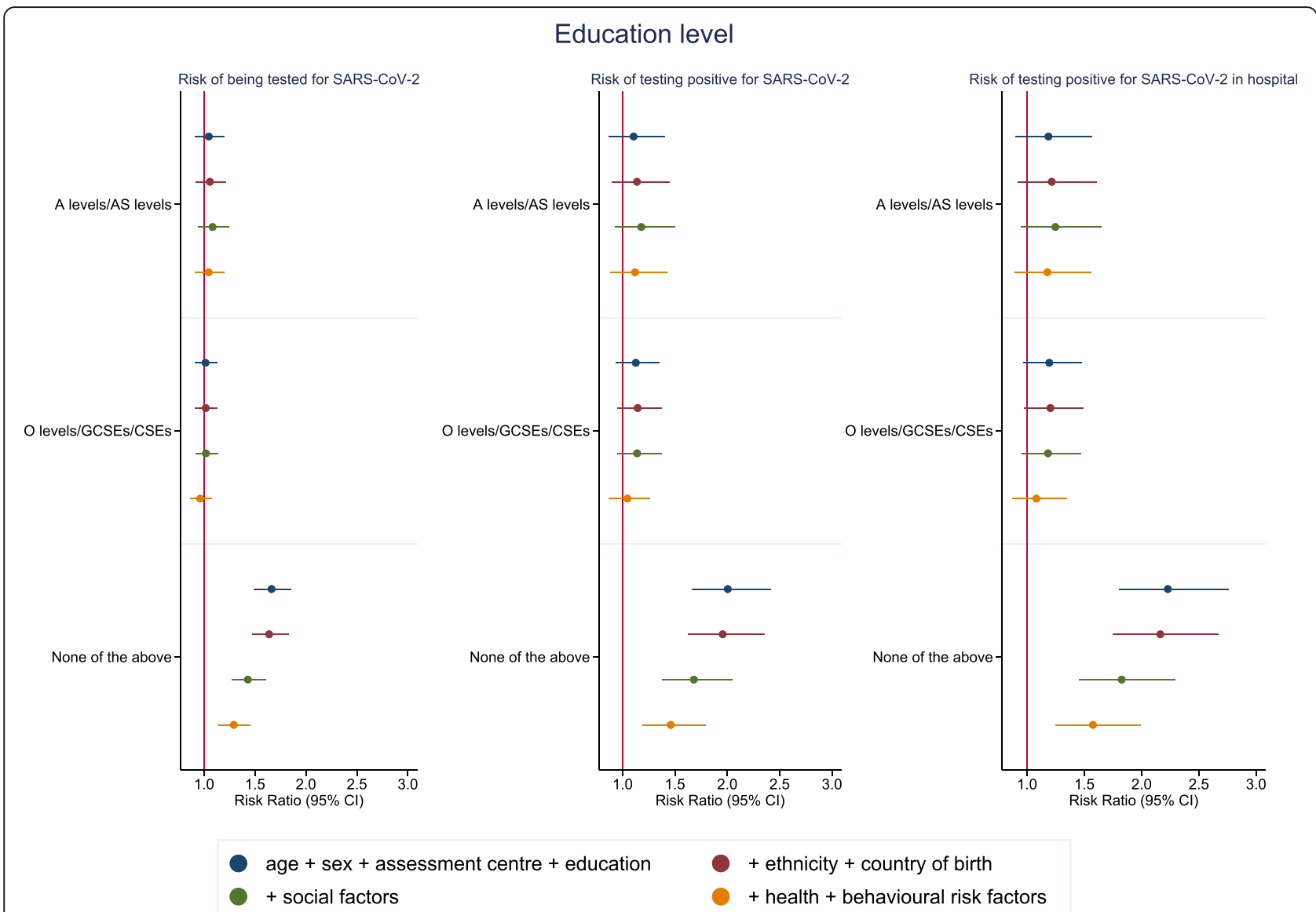

Fig. 4 Risk ratios for associations between highest educational level (degree educated as reference category) and SARS-CoV-2. Model 1: age, sex and assessment centre. Model 2: model 1 + ethnicity + country of birth. Model 3: model $2+$ social variables (healthcare worker, urbanicity, number of people per household, deprivation, tenure status, employment status, manual work). Model 4: model $3+$ health status variables (selfrated health, number of chronic conditions and longstanding illness) + behavioural risk factors (smoking, alcohol consumption and BMI).

Coefficient for the other groups are not shown

disadvantaged groups and some ethnic minority groups $[31,32]$. However, these are likely to operate as mediators rather than confounders.

Administrative data from health services has recently suggested an increased risk of severe COVID-19 disease within ethnic minority groups. The UK's Intensive Care National Audit \& Research Centre (ICNARC) analysed data on 5578 patients admitted to critical care up to 16th April 2020 and found black and Asian people comprised a high proportion of total patients $(11.2 \%$ and $14.9 \%$ respectively), although it was unclear whether these higher percentages were biased by most cases being initially seen in areas with high proportions of ethnic minority groups [33]. Similarly, data from the US Centers for Disease Control and Prevention also suggest a higher risk amongst black or African American people, but information on race was missing for approximately two-thirds of those diagnosed [34]. Analyses of administrative UK data have also suggested increased COVID19 mortality in black and south Asian ethnic groups
[26], which was only partly accounted for by socioeconomic differences [25]. However, the role of prior health and risk factors was not accounted for. Academic research on this topic has been limited to date. An ecological study of US counties has suggested that more socially vulnerable areas (which included greater numbers of people with socioeconomic disadvantage and ethnic minorities) were associated with higher COVID-19 case fatality rates [35]. Our study adds substantially to the evidence by finding that ethnicity appears to be an important predictor of laboratory-confirmed SARS-CoV2 infection that is only partly attenuated by a large range of potential mediators (such as socioeconomic position), as well as addressing concerns about numeratordenominator bias.

Our results suggest there is an urgent need for further research on how SARS-CoV-2 infection affects different ethnic and socioeconomic groups. Our findings warrant replication in other datasets, ideally including representative samples and across different countries. As the 
pandemic evolves, there is a need to monitor infection and disease outcomes by ethnicity and socioeconomic position. However, data to allow this disaggregation is often not available-record linkage could potentially help address this gap, particularly in settings where administrative register data are available. Given the differences in health risks across occupational groups [36], understanding the risks that the full range of key workers experience is also required. Lastly, other social groups, such as homeless people, prisoners and undocumented migrants, experience severe disadvantage and research is necessary to study these highly vulnerable populations too $[37,38]$.

\section{Conclusions}

The limited evidence available suggests that some ethnic minority groups, particularly black and south Asian people, are particularly vulnerable to the adverse consequences of COVID-19. Socioeconomic disadvantage and poorer pre-existing health do not explain all of this elevated risk. There is therefore a need to determine why this increased risk occurs. An immediate policy response is required to ensure the health system is responsive to the needs of ethnic minority groups. This should include ensuring that health and care workforces, which often rely on workers from minority ethnic populations, have access to the necessary personal protective equipment (PPE) to ensure they can work safely. Timely communication of guidelines to reduce the risk of being exposed to the virus is also required in a range of languages [39]. Previous evidence suggests ethnic minorities in the UK tend to receive reasonably equitable care in many, but not all, areas [40]. However, this is not the case in many other countries (such as the USA) where the adverse consequences of SARS-CoV-2 infection may be even worse. SARS-CoV-2 therefore has the potential to substantially exacerbate ethnic and socioeconomic inequalities in health [41], unless steps are taken to mitigate these inequalities. The data from this study may be helpful to inform allocation of more aggressive therapies in people with severe disease, or targeting preventative vaccination to at-risk groups, once evidence for such approaches becomes available.

\section{Supplementary information}

Supplementary information accompanies this paper at https://doi.org/10. 1186/s12916-020-01640-8

Additional file 1 : Figure S1. Flowchart of study participants. Table S1. Missing data by ethnicity, socioeconomic deprivation and education level. Table S2. Description of the sample by ethnicity. Table S3. Description of SARS-CoV-2 test results within UK Biobank by ethnicity and socioeconomic position. Table S4. Ethnicity and risk of testing positive. Table S5. Ethnicity and risk of testing positive in hospital. Table S6. Ethnicity and risk of being tested. Table S7. Ethnicity (more defined groups) and risk of testing positive. Table S8. Ethnicity (more defined groups) and risk of testing positive in hospital. Table S9. Ethnicity (more defined groups) and risk of being tested. Table S10. Socioeconomic deprivation and risk of testing positive. Table S11. Socioeconomic deprivation and risk of testing positive in hospital. Table $\mathbf{S 1 2}$. Socioeconomic deprivation and risk of being tested. Table S13. Education level and risk of testing positive. Table S14. Education level and risk of testing positive in hospital. Table S15. Education level and risk of being tested. Table S16. Ethnicity and risk of testing positive amongst those tested. Table S17. Socioeconomic deprivation and risk of testing positive amongst those tested. Table S18. Education level and risk of testing positive amongst those tested.

\section{Abbreviations}

BMI: Body mass index; Cl: Confidence interval; COVID-19: Coronavirus disease 2019; CSE: Certificate of Secondary Education; GCSE: General Certificate of Secondary Education; ICNARC: Intensive Care National Audit \& Research Centre; NHS: National Health Service; PPE: Personal protective equipment; RR: Risk ratio; SARS-CoV-2: Severe acute respiratory syndrome coronavirus-2; SOC: Standard Occupational Classification; UK: United Kingdom

\section{Acknowledgements}

We are grateful to the UK Biobank participants. This research has been conducted using the UK Biobank resource under Application 41686.

\section{Authors' contributions}

SVK, KOD and JPP conceived the idea for the paper. CLN conducted the analysis. All authors contributed to the interpretation of the findings. CLN and SVK jointly wrote the first draft. All authors critically revised the paper for intellectual content and approved the final version of the manuscript. The corresponding authors (SVK and CLN) had full access to all the data in the study and had final responsibility for the decision to submit for publication. All authors read and approved the final manuscript.

\section{Funding}

CLN acknowledges funding from a Medical Research Council Fellowship (MR/R024774/1). ED and SVK acknowledge funding from the Medical Research Council (MC_UU_12017/13) and Scottish Government Chief Scientist Office (SPHSU13). SVK also acknowledges funding from a NRS Senior Clinical Fellowship (SCAF/15/02). The funder of the study had no role in the study design, data collection, data analysis, data interpretation or writing of the report.

\section{Availability of data and materials}

The data that support the findings of this study are available from UK Biobank (https://www.ukbiobank.ac.uk), but restrictions apply to their availability. These data were used under licence for the current study and so are not publicly available. The data are available from the authors upon reasonable request and with permission of UK Biobank.

\section{Ethics approval and consent to participate}

UK Biobank received ethical approval from the NHS National Research Ethics Service North West (11/NW/0382; 16/NW/0274). All participants provided written informed consent before enrolment in the study, which was conducted in accordance with the Declaration of Helsinki. The study protocol is available online (https://www.ukbiobank.ac.uk/wp-content/ uploads/2011/11/UK-Biobank-Protocol.pdf).

Consent for publication

Not applicable

\section{Competing interests}

JPP is a member of the UK Biobank Steering Committee. Apart from the funding acknowledged below, we declare no other competing interests.

\section{Author details}

'Institute of Health \& Wellbeing, College of Medical, Veterinary and Life Sciences, University of Glasgow, Glasgow G12 8RZ, UK. ${ }^{2}$ General Practice and Primary Care, Institute of Health and Wellbeing, College of Medical, Veterinary and Life Sciences, University of Glasgow, 1 Horselethill Road, 
Glasgow G12 9LX, UK. ${ }^{3}$ MRC/CSO Social \& Public Health Sciences Unit, University of Glasgow, Top floor, 200 Renfield Street, Glasgow G2 3QB, UK. ${ }^{4}$ BHF Glasgow Cardiovascular Research Centre, Institute of Cardiovascular and Medical Sciences, College of Medical, Veterinary and Life Sciences, University of Glasgow, Glasgow G12 8TA, UK. ${ }^{5}$ Public Health Scotland, Meridian Court, 5 Cadogan Street, Glasgow G2 6QE, UK.

\section{Received: 24 April 2020 Accepted: 18 May 2020}

Published online: 29 May 2020

\section{References}

1. World Health Organization: Coronavirus disease 2019 (COVID-19): situation report - 91. In. Geneva: World Health Organization; 2020. https://www.who. int/emergencies/diseases/novel-coronavirus-2019/situation-reports/. Accessed 20 Apr 2020

2. Sattar N, McInnes IB, JJV M: Obesity a risk factor for severe COVID-19 infection: multiple potential mechanisms. Circulation 2020. In press. https:// doi.org/10.1161/CIRCULATIONAHA.120.047659.

3. Zhou F, Yu T, Du R, Fan G, Liu Y, Liu Z, Xiang J, Wang Y, Song B, Gu X, et al. Clinical course and risk factors for mortality of adult inpatients with COVID19 in Wuhan, China: a retrospective cohort study. Lancet. 2020;395(10229): 1054-62.

4. Wu C, Chen X, Cai Y, Xia Ja, Zhou X, Xu S, Huang H, Zhang L, Zhou X, Du C et al: Risk factors associated with acute respiratory distress syndrome and death in patients with coronavirus disease 2019 pneumonia in Wuhan, China. JAMA Internal Med. 2020. https://doi.org/10.1001/jamainternmed. 2020.0994.

5. Myers EM. Compounding Health Risks and Increased Vulnerability to SARSCoV-2 for Racial and Ethnic Minorities and Low Socioeconomic Status Individuals in the United States. Preprints. 2020;2020040234. https://doi.org/ 10.20944/preprints202004.0234.v1.

6. Hutchins SS, Fiscella K, Levine RS, Ompad DC, McDonald M. Protection of racial/ethnic minority populations during an influenza pandemic. Am J Public Health. 2009;99(S2):S261-70.

7. Khunti K, Singh AK, Pareek M, Hanif W. Is ethnicity linked to incidence or outcomes of covid-19? BMJ. 2020;369:m1548.

8. Khan O. A sense of place: retirement decisions among older Black and minority ethnic people. London: Runnymede Trust; 2012.

9. Dowd JB, Andriano L, Brazel DM, Rotondi V, Block P, Ding X, Liu Y, Mills MC Demographic science aids in understanding the spread and fatality rates of COVID-19. Proc Natl Acad Sci. 2020;117(18):9696-8.

10. McNair E. Measuring use of health services by equality group. Edinburgh: NHS National Services Scotland; 2017.

11. Sudlow C, Gallacher J, Allen N, Beral V, Burton P, Danesh J, Downey P, Elliott $P$, Green J, Landray M. UK biobank: an open access resource for identifying the causes of a wide range of complex diseases of middle and old age. PLoS Med. 2015;12(3):e1001779. https://doi.org/10.1371/journal.pmed. 1001779.

12. Jacob A, Justine R, Naomi A, Derrick C, Daniel W, David W, Anne-Marie OC. Dynamic linkage of COVID-19 test results between Public Health England's Second Generation Surveillance System and UK Biobank; 2020.

13. Bhopal RS, Gruer L, Cezard G, Douglas A, Steiner MFC, Millard A, Buchanan D, Katikireddi SV, Sheikh A. Mortality, ethnicity, and country of birth on a national scale, 2001-2013: a retrospective cohort (Scottish Health and Ethnicity Linkage Study). PLoS Med. 2018;15(3):e1002515.

14. Townsend P. Deprivation. J Soc Policy. 1987;16(2):125-46.

15. Hagenaars SP, Gale CR, Deary IJ, Harris SE. Cognitive ability and physical health: a Mendelian randomization study. Sci Rep. 2017;7(1):2651.

16. Honkaniemi H, Juárez SP, Katikireddi SV, Rostila M. Psychological distress by age at migration and duration of residence in Sweden. Soc Sci Med. 2020; 250:112869.

17. Jani BD, Hanlon P, Nicholl BI, McQueenie R, Gallacher Kl, Lee D, Mair FS. Relationship between multimorbidity, demographic factors and mortality: findings from the UK Biobank cohort. BMC Med. 2019;17(1):74.

18. Office for National Statistics. Standard occupational classification 2000 London: The Stationery Office; 2000.

19. Zou G. A modified Poisson regression approach to prospective studies with binary data. Am J Epidemiol. 2004;159(7):702-6.

20. Bhopal RS. Migration, ethnicity, race, and health in multicultural societies. Oxford: Oxford University Press; 2014.
21. Agyemang C, Bhopal R, Bruijnzeels M. Negro, Black, Black African, African Caribbean, African American or what? Labelling African origin populations in the health arena in the $21^{\text {st }}$ century. J Epidemiol Community Health. 2005;59(12):1014-8.

22. Munafò MR, Tilling K, Taylor AE, Evans DM, Davey Smith G. Collider scope: when selection bias can substantially influence observed associations. Int Epidemiol. 2017;47(1):226-35.

23. Griffith G, Morris TT, Tudball M, Herbert A, Mancano G, Pike L, Sharp GC, Palmer TM, Davey Smith G, Tilling K et al. Collider bias undermines our understanding of COVID-19 disease risk and severity. medRxiv 2020:2020. 2005.2004.20090506. https://doi.org/10.1101/2020.05.04.20090506.

24. Batty GD, Gale CR, Kivimäki M, Deary IJ, Bell S. Comparison of risk factor associations in UK Biobank against representative, general population based studies with conventional response rates: prospective cohort study and individual participant meta-analysis. BMJ. 2020;368:m131.

25. Office for National Statistics: Coronavirus (COVID-19) related deaths by ethnic group, England and Wales: 2 March 2020 to 10 April 2020. 2020.

26. Aldridge R, Lewer D, Katikireddi S, Mathur R, Pathak N, Burns R, Fragaszy E, Johnson A, Devakumar D, Abubakar I et al. Black, Asian and Minority Ethnic groups in England are at increased risk of death from COVID-19: indirect standardisation of NHS mortality data [version 1; peer review: awaiting peer review]. Wellcome Open Res 2020, 5(88). https://doi.org/10.12688/ wellcomeopenres.15922.1.

27. Katikireddi SV, Skivington K, Leyland AH, Hunt K, Mercer SW. The contribution of risk factors to socioeconomic inequalities in multimorbidity across the lifecourse: a longitudinal analysis of the Twenty-07 cohort. BMC Med. 2017;15(1):152.

28. Millett C, Gray J, Saxena S, Netuveli G, Khunti K, Majeed A. Ethnic disparities in diabetes management and pay-for-performance in the UK: the Wandsworth prospective diabetes study. PLoS Med. 2007:4(6):e191.

29. Stand up, step forward, save lives. https://www.nhsprofessionals.nhs.uk/en/ Joining-NHSP/Latest-News/Detail?Id=STAND-UP-STEP-FORWARD-SAVE-LIVES Accessed 10 May 2020.

30. Zhao X, Zhang B, Li P, Ma C, Gu J, Hou P, Guo Z, Wu H, Bai Y. Incidence, clinical characteristics and prognostic factor of patients with COVID-19: a systematic review and meta-analysis. medRxiv 2020. https://doi.org/10.1101/ 2020.03.17.20037572

31. Banerjee A, Pasea L, Harris S, Gonzalez-Izquierdo A, Torralbo A, Shallcross L, Noursadeghi M, Pillay D, Sebire N, Holmes C et al. Estimating excess 1-year mortality associated with the COVID-19 pandemic according to underlying conditions and age: a population-based cohort study. The Lancet. https:// doi.org/10.1016/S0140-6736(20)30854-0.

32. Kurian AK, Cardarelli KM. Racial and ethnic differences in cardiovascular disease risk factors: a systematic review. Ethn Dis. 2007;17(1):143.

33. Intensive Care National Audit \& Research Centre. London: ICNARC report on COVID-19 in critical care; 2020. https://www.icnarc.org/Our-Audit/Audits/ Cmp/Reports. Accessed 20 Apr 2020.

34. Cases of Coronavirus Disease (COVID-19) in the U.S. https://www.cdc.gov/ coronavirus/2019-ncov/cases-updates/cases-in-us.html. Accessed 20 Apr 2020

35. Nayak A, Islam SJ, Mehta A, Ko Y-A, Patel SA, Goyal A, Sullivan S, Lewis TT, Vaccarino V, Morris AA et al: Impact of social vulnerability on COVID-19 incidence and outcomes in the United States. medRxiv 2020:2020.2004. 2010.20060962. https://doi.org/10.1101/2020.04.10.20060962.

36. Katikireddi SV, Leyland AH, McKee M, Ralston K, Stuckler D. Patterns of mortality by occupation in the United Kingdom, 1991-2011: a comparative analysis of linked census-mortality records over time and place. Lancet Public Health. 2017:2(11):e501-12.

37. Aldridge RW, Story A, Hwang SW, Nordentoft M, Luchenski SA, Hartwell G, Tweed EJ, Lewer D, Vittal Katikireddi S, Hayward AC. Morbidity and mortality in homeless individuals, prisoners, sex workers, and individuals with substance use disorders in high-income countries: a systematic review and meta-analysis. Lancet. 2018;391(10117):241-50.

38. Abubakar I, Aldridge RW, Devakumar D, Orcutt M, Burns R, Barreto ML, Dhavan P, Fouad FM, Groce N, Guo Y, et al. The UCL \& Lancet Commission on Migration and Health: the health of a world on the move. Lancet. 2018; 392(10164):2606-54

39. Chin MH, Walters $A E$, Cook SC, Huang ES. Interventions to reduce racial and ethnic disparities in health care. Med Care Res Rev. 2007;64(5 suppl):7S-28S.

40. Katikireddi SV, Cezard G, Bhopal RS, Williams L, Douglas A, Millard A, Steiner M, Buchanan D, Sheikh A, Gruer L. Assessment of health care, hospital 
admissions, and mortality by ethnicity: population-based cohort study of health-system performance in Scotland. Lancet Public Health. 2018;3(5): e226-36.

41. Douglas M, Katikireddi SV, Taulbut M, McKee M, McCartney G. Mitigating the wider health effects of covid-19 pandemic response. BMJ. 2020;369:m1557.

\section{Publisher's Note}

Springer Nature remains neutral with regard to jurisdictional claims in published maps and institutional affiliations.

Ready to submit your research? Choose BMC and benefit from:

- fast, convenient online submission

- thorough peer review by experienced researchers in your field

- rapid publication on acceptance

- support for research data, including large and complex data types

- gold Open Access which fosters wider collaboration and increased citations

- maximum visibility for your research: over $100 \mathrm{M}$ website views per year

At $B M C$, research is always in progress.

Learn more biomedcentral.com/submissions 